\title{
SUSCITAR A PALAVRA A PARTIR DE IMAGENS DE FICÇÃo: UMA QUESTÃo DE CIÊNCIA PÚBLICA OU DE ARTE PÚBLICA?
}

\author{
Pascal Cesaro \\ Laboratório PRISM - Perceção Representações Imagem Som Música, Universidade Aix-Marselha, França \\ Pierre Fournier \\ Laboratório LAMES - Laboratório de Sociologia Mediterrânica, Universidade Aix-Marselha, França
}

\begin{abstract}
Resumo
Partindo de um dispositivo de entrevistas particular, recentemente testado como parte de um projeto de pesquisa interdisciplinar que associa Sociologia e Cinema, este artigo propõe uma reflexão sobre os problemas envolvidos no uso da vídeo-elicitação, isto é, da condução de entrevistas suscitadas pela visualização de imagens, neste caso imagens de ficção realistas. Primeiro, podemos ver aí um desafio para a pesquisa em Ciências Sociais, quando a vídeo-elicitação tenta superar uma dificuldade conhecida, que está associada ao risco de imposição da problemática aos entrevistados pelo investigador no contexto da pesquisa por entrevista. Segundo, neste caso é possível extrair, de maneira mais ampla, uma questão para a ciência pública, cidadã, que esteja atenta à implicação dos atores sociais nas perguntas e nas suas análises, com respeito pela sua experiência prática para entrar numa forma de co-construção de conhecimento. Finalmente, podemos detetar aí um desafio artístico com a abertura de um novo repertório de expressão pública, combinando, numa forma de arte pública: a produção artística de um tempo passado (o arquivo audiovisual de ficção); a remobilização em escritos multimédia evocando emoção e reação; e o comprometimento por meio de novas mediações tecnológicas numa apropriação estética da fricção da experiência sensível. Nestas condições de reutilização, os arquivos audiovisuais de ficção poderiam encontrar um novo valor que possa ser associado ao movimento de patrimonialização e à busca de raízes que caracterizem as nossas sociedades globalizadas e em mutações permanentes.
\end{abstract}

\section{Palavras-chave}

entrevista; sociologia pública; arquivo; vídeo-elicitação; ficção

\section{RAISING THE WORD FROM IMAGES OF FICTION: A MATTER OF PUBLIC SCIENCE OR PUBLIC ART?}

\begin{abstract}
Based on a novel approach to interviewing that was recently applied in the context of an interdisciplinary research project combining sociology and cinema, this article proposes a discussion of the stakes involved in the use of video-elicitation, i.e. the conducting of interviews prompted by the viewing of images, and in this case realistic fiction images. One can first see video-elicitation as an opportunity for social science research when it seeks to overcome a wellknown difficulty associated with the risk of having the researcher imposing issues on the respondents in the context of an interview survey. On a broader level, one can also see it as an opportunity for a public, citizen-based science that is attentive to the involvement of social actors in their questioning and analysis, and that respects their practical expertise and integrates the latter
\end{abstract}


into a form of co-construction of knowledge. Finally, it can be seen as an artistic opportunity, with the opening up of a new repertoire of public expression combining artistic productions from the past (fictional audio-visual archives), the renewed use of these productions in multimedia works that stimulate emotions and reactions, and the proposal, through new technological media, of an aesthetic appropriation that is closer to sensory experience, and that takes the form of public art. Under these conditions of use, audio-visual fiction archives could find a renewed value that one could associate with the heritage movement and the search for roots that characterize our globalized and ever-changing societies.

\section{KEYWORDS}

interview, public sociology, archive, video-elicitation, fiction

A revolução digital permite hoje aceder facilmente a arquivos de imagens que poderiam encontrar novos usos no movimento patrimonial e na busca de raízes que caracterizam as nossas sociedades globalizadas e em mutações permanentes. Este é o caso das imagens de ficção que foram produzidas pelo cinema e pela televisão para serem compartilhadas por um público amplo'. A difusão de imagens no passado é uma garantia de que os profissionais do audiovisual consideraram, em seu tempo, que elas atenderam às expectativas da época em termos de entretenimento, o que lhes confere uma segunda dimensão: de fonte de pesquisa para a História Cultural. Por outro lado, as imagens filmadas e montadas com um propósito realista constituem, de fato, uma possível fonte de memória para os lugares que passaram por transformações, para exercícios profissionais que mudaram ou para estilos de vida que podem ter desaparecido. Atualmente, o desenvolvimento da tecnologia digital facilita a indexação dessas imagens para sua identificação. Ela simplifica o uso de ferramentas de montagem e de hibridação em escritas multimédia e torna mais fluido o diálogo com profissionais de imagem, tendo em vista a reutilização dessas fontes numa nova vocação pública. Assim sendo, estas fontes poderiam encontrar um novo valor no movimento de patrimonialização e na busca de raízes que caracterizem as nossas sociedades globalizadas e em permanente mudança? Um tal novo valor situar-se-ia nos planos do conhecimento científico e da criação artística? E que veiculam de específico para esses empreendimentos de ciência ou arte, os trabalhos da mente que foram concebidos para ter uma função de distração a partir de formas de narração realista?

Evidentemente, a ficção realista se distancia do real: ela joga com o real. Produzir imagens realistas de um filme de ficção romanesca é jogar com o enquadramento, é escolher frações da realidade e excluir outras. Olhar para o resultado também é buscar prazer em fingir acreditar na realidade das imagens sem perder de vista, é claro, que se está numa sala escura ou em frente a uma tela e no jogo entre um autor e o destinatário da sua obra, o primeiro agindo com o segundo como um gato com um rato para levá-lo a pistas falsas que parecem reais, antes de lhe entregar, in fine, a verdade da história

\footnotetext{
' Aqui excluem-se os filmes de inspiração antropológica que exploram a Primavera da ficção para a sua narração, como $\mathrm{Na}$ nook of the North, por R. Flaherty (1922) ou Farrebique por G. Rouquier (1946) e Biquefarre também por G. Rouquier (1983).
} 
de personagens que são... imaginários. Eis rapidamente esboçada a forma de "simulação lúdica compartilhada" (Schaeffer, 1999, 146) que caracteriza a ficção no audiovisual: concordar em suspender o seu julgamento da realidade e regozijar-se em pensar que se tem todos os elementos para adivinhar a resolução do enigma ou, em qualquer caso, que temos todos os elementos para avaliar o realismo desta resolução. Este teste de realidade não mobiliza somente os saberes do realizador e dos atores. $O$ intertexto do espetador também entra em jogo. O espetador aproveita as "iniciações miméticas" (Schaeffer, 2002, s. p.) para mobilizar a sua experiência pessoal do mundo em diálogo com aquela que os personagens parecem ter, para avaliar a sua "verdade", isto é, a veracidade, a plausibilidade, e para comentar a sua justeza, a relevância moral.

Por consequência, a imagem da ficção não é, obviamente, um traço da realidade, mas um traço do trabalho de tradução em realismo que os profissionais podem produzir num certo ambiente de soluções técnicas e com uma certa definição das expetativas do público, em termos de narração realista para benefício do entretenimento. Não se exclui que a ficção audiovisual se apoia na realidade, a priori, a ficção cita o real apenas por conveniência: quando é mais simples torná-la realista com a própria realidade, por exemplo usando um elemento de decoração ou no caso de um objeto que é retomado num plano sem alteração. Como este empréstimo do real não é assinalado ou certificado, é incerto e perigoso inferir a realidade a partir da imagem da ficção.

Qualquer possibilidade de conhecimento através da imagem da ficção não deve por isso ser descartada. O prazer do jogo com a realidade vivida pelo espectador de ficção pode constituir a fonte de outra forma de conhecimento quando o quadro de visualização não é um momento de divertimento, mas um momento de vídeo-elicitação em resposta ao convite de um investigador de Ciências Sociais e quando aquele que é convidado a falar a partir das imagens mantém uma relação de proximidade com a ficção: porque compartilha o lugar de vida, a profissão ou o modo de vida dos personagens do filme. A intenção do pesquisador ao envolver o entrevistado num dispositivo de entrevistas geradas a partir de imagens de ficção é de tirar partido dessa proximidade da realidade ficcional com aquela do entrevistado. Trata-se de pedir-lhe para falar sobre a sua experiência pessoal em certas situações, propondo-lhe comentar as ações de personagens de ficção em situações semelhantes. É uma outra maneira de lidar com o virtual do audiovisual e com o real da experiência, diferente da modalidade da simulação lúdica compartilhada que ocorre na projeção do divertimento. É querer, para o pesquisador, aceder ao significado que os entrevistados dão à realidade confrontando-a com as suas próprias trajetórias. É aceitar, para o espectador, dialogar sobre este assunto, falar de si mesmo face ao real, fazendo eco à narrativa virtual que é apresentada no filme. O prazer do espectador torna-se, se ele se envolver na relação de pesquisa, em ajudar o pesquisador a responder a certas perguntas com o seu concurso, numa ciência participativa, colaborativa, particularmente atenta à sua situação simultaneamente singular e inscrita num ambiente coletivo.

É este dispositivo de vídeo-elicitação que os autores do presente artigo experimentaram recentemente no quadro de um projeto interdisciplinar de pesquisa associando a 
Sociologia ao Cinema, o qual propomos aqui pormenorizar afim de considerar um deslocamento possível de um assunto da ciência em direção a uma ciência pública e talvez a uma arte pública, a partir da reutilização de arquivos audiovisuais.

\section{UM DISPOSITIVO PARA SUPERAR OS DESAFIOS DA IMPOSIÇÃo DE PROBLEMÁTICA}

A reutilização de imagens de arquivos de ficção (neste caso, sequências de uma série de televisão produzida na década de 1960) foi a base de uma investigação sociológica por meio de entrevistas, explorando a vídeo-elicitação no intuito de esclarecer o que significa conviver com a energia nuclear, fazer com esta indústria de risco quando se vive muito perto dela, ou mesmo quando se trabalha lá (Cesaro \& Fournier, 2015). O recurso a um dispositivo que provoca a palavra a partir de uma projeção de imagens visa superar uma dificuldade de pesquisa. Este é um problema bastante clássico para a Sociologia: podemos lidar com todos os assuntos que interessam aos sociólogos através de entrevistas? Bourdieu, Chamboredon e Passeron mostraram que não se pode investigar tudo com questionários fechados: corre-se efetivamente um risco de "imposição de problemáticas" (1968, p. 65), formulando-se uma pergunta e possíveis respostas ao submete-las aos entrevistados. Elas orientam o interlocutor para o significado que ele deve dar à questão e coloca-o na obrigação de lhe responder, aceitando certos pressupostos do investigador. Pode-se pensar que, diante dessas limitações do inquérito quantitativo, a pesquisa qualitativa por meio de entrevistas não-diretivas propunha uma escuta mais profunda, mas este não é o caso para todos os assuntos. A polarização do debate público sobre certos temas complica o trabalho do sociólogo. Ele precisa enfrentar situações de fala que podem ser consideradas impedidas, entravadas, parasitadas por posições polarizadas que são formuladas num registro abstrato, às vezes distante da própria experiência das pessoas. Podemos citar exemplos, como falar sobre a colonização francesa ou a guerra da Argélia, a SIDA ou a homossexualidade, fazer críticas à indústria em tempos de desemprego em nome da proteção ambiental... o entrevistado é novamente tentado a responder em termos que não lhe são próprios. Desta vez, não são especialmente os termos do investigador, mas os do debate público, aqueles que o debate público tem constituído em posições legítimas, mesmo que sejam posturas bastante opostas. $O$ problema colocado então é de se perguntar se os propósitos do investigador esclarecem sobre as referências concretas a que o entrevistado se irá referir no momento de decidir quanto à sua abordagem sobre o assunto, ou se esses propósitos lançam luz somente sobre a perceção que os atores têm daquilo que os protege de um julgamento moral injusto sobre si mesmos por parte de um desconhecido, o investigador. O sociólogo interessado na situação particular da pessoa que ele encontra, deve recolher tais palavras abstratas, formuladas nas amplas categorias de debate público, e pode tomá-las como determinantes da conduta prática do entrevistado? Ou deve preferir recolher elementos da prática do entrevistado que realmente esclareçam sobre aquilo que o orienta?

No exemplo da indústria nuclear nos países onde há uma contestação ao princípio desta atividade (por razões ambientais, económicas ou de pacifismo), quando se 
pretende questionar as populações que vivem perto das instalações nucleares sobre a sua relação com o território, muitas vezes deparamo-nos com a sua relutância em responder: estão autorizadas a falar livremente sobre isso ou é preferível que se calem? Este silêncio justifica-se, eventualmente, porque trabalham lá e o seu empregador pediu-lhes para não discutirem o assunto com qualquer um (seja por sigilo militar, sigilo industrial, segredo de segurança contra piratagem...). Mas também porque nunca se sabe bem com quem se está a falar: o entrevistador é provavelmente pró-nuclear ou antinuclear, e vai julgá-los com base no que eles vão dizer. Isto obriga-os, por sua vez, a tomar partido, seja pelo pró-nuclear, seja pelo antinuclear, porque é assim que eles pressentem que o mundo é dividido do ponto de vista do entrevistador. E não importa se eles desejam ardentemente continuar a trabalhar na indústria nuclear, desde que seja organizada de forma diferente. Ou se desejam acabar com a energia nuclear no seu território, a fim de poderem envolver-se, com um custo mais baixo, em novas atividades que eles apreciam, mas que são incompatíveis com esta presença industrial e que eles poderiam implementar em outros lugares, sob condição de deslocarem a sua habitação.

A polarização do debate público sobre a energia nuclear, portanto, requer a busca de soluções por parte da etnografia, no sentido de se impregnar da situação dos atores, a fim de evitar esses propósitos, que não se sabe se concernem à análise da situação de vida ou a uma leitura da relação do inquirido com o investigador. Mas a observação in situ nem sempre é possível sobre tal assunto. Ela o é para o trabalho quanto à energia nuclear, pelo menos para o trabalho menos qualificado (como o da manutenção, Fournier, 2012) e, para o trabalho altamente qualificado². Essa observação in situ é pouco factível no que tange aos trabalhadores que residem perto das instalações nucleares (Girard, 2009). É muito menos óbvia, se não impossível, quando se trata da vida cotidiana, ordinária e familiar a longo prazo. Isso exigiria um investimento muito grande para um conhecimento muito parcial.

\section{UMA EXPERIÊNCIA DE COLABORAÇÃO COM OS INQUIRIDOS}

A descoberta, nos fundos dos arquivos do Institut National de l'Audiovisuel, de uma novela romanesca da televisão pública, Les Atomistes (Keigel,1968), facultou uma ideia alternativa. Esta novela, filmada num centro nuclear francês, apresenta o trabaIho de uma equipa de investigadores e técnicos desse setor. O processo de a mostrar aos trabalhadores do campo das imagens deste filme, poderia servir de suporte para entrevistas sobre a sua experiência de vida num tal cenário técnico e de gestão e no seu território de instalação? Os testemunhos recolhidos a partir deste dispositivo são surpreendentemente concretos e precisos sobre os elementos da prática. Eles estão longe do discurso estereotipado ou do silêncio atrás do qual os entrevistados muitas vezes se refugiam face a um assunto tão controverso. Esta é uma oportunidade para nos

\footnotetext{
${ }^{2}$ Passivlter, programa de Estudos de Ciência e Tecnologia, em curso, sobre a mobilização de uma equipa multidisciplinar de pesquisadores face a um problema de saúde ambiental a ser antecipado no desenvolvimento de um grande equipamento de pesquisa.
} 
perguntarmos sobre as contribuições que a vídeo-elicitação, para além da foto-elicitação introduzida na antropologia por Collier e Collier a partir de fotos tiradas durante o inquérito (1967), pode trazer à investigação sociológica para escapar ao risco de imposição de uma problemática que ameaça os investigadores. E é também uma oportunidade para ver aquilo que o uso de imagens de ficção muda no sentido de integrar os entrevistados na pesquisa e de suscitar neles narrativas sobre as suas próprias experiências de vida, longe dos discursos marcados pelos debates constituídos sobre o tema da energia nuclear. A ficção revela ter qualidades para tornar o questionamento do sociólogo compreensível e apropriado para o interlocutor e para incentivar o sociólogo a entrar numa colaboração profunda com o entrevistado.

A novela Les Atomistes, dirigida por Leonardo Keigel a pedido da televisão pública e transmitida em fevereiro-março de 1968 em episódios de 13 minutos entre as 19h45' e as 2oh, apresenta as aventuras de um grupo de cientistas e de técnicos em torno de uma atividade de pesquisa sobre o uso da radioatividade com fins civis para o desenvolvimento de um material com novas propriedades. Coproduzido pela Office de Radiodiffusion Télévision Française (ORTF) e pela empresa de produção Paris-Cité, esta novela encarna o surpreendente encontro de uma forma de entretenimento tão marcante como a telenovela que precede o noticiário da noite com um assunto tão grave como a energia nuclear no momento da Guerra Fria. Ao mobilizar esta telenovela no contexto da pesquisa, propõe-se aos entrevistados uma colaboração com o investigador, que pede ajuda para situar a relevância descritiva das imagens do filme, o seu valor de verdade e as falhas e deficiências na narração. Numa parceria entre sociólogo e investigador de cinema, a equipa de investigação construiu um filme de apoio para o dispositivo de vídeo-elicitação a partir dos 26 episódios da telenovela, ou seja, cinco horas de filme de ficção. Era impossível mostrar tudo às pessoas contatadas na investigação. Foi necessário escolher alguns assuntos de acordo com os interesses do investigador. Para além disso, não havia nenhuma dúvida sobre o irrealismo de muitas imagens. Ainda assim, encontravam-se imagens muito precisas de certos lugares, cenas de trabalho e interações no trabalho. Embora a novela remonte à década de 1960, as imagens pareciam muito justas para o sociólogo que realizou observação participante deste universo de trabalho na década de 1980 e 1990. Deste modo, a equipa empreendeu um trabalho de adaptação, de remontagem de extratos da novela para reagrupar várias sequências dos diferentes episódios, a fim de obter um filme de 20 minutos que propõe uma narrativa coerente, com as imagens e vozes da década de 1960, mas no ritmo da televisão dos anos 2000, nomeadamente utilizando elipses que dinamizam a narrativa. Nesta ocasião, a equipa tentou descartar as imagens mais fantasistas da novela. Tais distorções em relação à verdade do trabalho no setor não apresentaram problemas na produção de uma série de televisão para o público em geral, mas provavelmente desacreditariam o nosso pedido de ajuda aos espetadores escolhidos para julgar o valor de verdade de imagens supostamente realistas, e de eco destas imagens na experiência pessoal desses interlocutores. 
Em seguida, a equipa entrevistou pessoas a quem sugeriram "vir e ajudar" a determinar a natureza realista do filme. Os investigadores propuseram a essas pessoas verem o filme antes de falarem sobre ele. Depois disso, a equipa trocou impressões com elas e, no final da entrevista, foi realizado um visionamento coletivo, incluindo momentos de paragem em certas cenas onde os espetadores, em princípio, não teriam pensado evocar algo útil para a investigação sobre as ligações entre os sítios nucleares e os seus territórios de implantação. Esta estratégia de pesquisa funcionou.

Primeiro, o dispositivo de vídeo-elicitação de imagens de ficção constitui um bom pretexto para superar certas precauções por parte dos entrevistados face a uma interação temida como dolorosa, ou mesmo embaraçosa com alguém que eles não conhecem e que têm dificuldade em situar, cujas intenções eles lutam por entender, e cujo julgamento às vezes receiam. Na verdade, a equipa do projeto, ao pedir-lhes ajuda no que apresenta como um jogo de decifração de imagens, joga com a curiosidade de pessoas, que se perguntam o que lhes será mostrado (ninguém ouviu falar da novela que nunca foi retransmitida), tanto para aqueles que trabalham no local da central nuclear, quanto para os demais. O que aparece então como um trabalho de especialização em imagens é "seguro" para eles, porque as imagens são totalmente "discutíveis": a narrativa romanesca de uma novela de televisão é irrealista por definição. Ninguém será surpreendido com isso. Ninguém se sentirá prejudicado pelo que atestarmos. Por outro lado, os entrevistados podem querer salientar que a telenovela é bastante realista sobre um ou outro ponto e esta informação é de primordial importância para o investigador que tem dificuldade para se situar no setor.

Em segundo lugar, o dispositivo de vídeo-elicitação de imagens de ficção permite o acesso a um determinado tipo de palavra, a relatos de práticas diárias que ecoam as ações representadas na ficção sem serem reduzidas a um repertório de lugares-comuns que a pessoa se acostumou a formular em narrativas edificantes para certas circunstâncias do diálogo (como a educação dos seus filhos ou a receção de um novo colega no trabalho). Essas palavras da prática quotidiana que interessam ao investigador, essas observações da prática que o pesquisador delega ao entrevistado, naturalmente ecoam com o que é apresentado no filme. Mas eles também levam a evocar o que não se encontra no filme: o investigador pode, assim, expressar o seu pesar pelo facto de que um dado elemento não é mencionado no filme e a pessoa responde, detalhando a sua prática singular sobre este ponto ausente, sem sentir vergonha de referir elementos sobre a situação pessoal, que não são sintetizados em amplas categorias de abstração, que permanecem próximas da experiência sensível. Assim sendo, a ficção romanesca funciona como uma espécie de retrato filmado do entrevistado que the seria mostrado e que ele seria solicitado a corrigir, para comentar a esclarecer ao pesquisador o fato de que, na sua vida ordinária, ele executa regularmente uma tal ação e muito mais raramente uma outra. A telenovela é entendida assim enquanto um dispositivo fílmico indireto da auto-confrontação . É uma espécie de observação antecipada dele próprio, que situa o entrevistado no lugar do observador e leva-o a questionar esses dados, dando-lhe a

\footnotetext{
3 Sobre a clássica auto-confrontação cinematográfica, ver Theureau (2010).
} 
oportunidade de interpretar, à sua própria maneira, o significado produzido pelas imagens. A imagem provoca a formulação de uma palavra que irá redefinir o significado da sua representação, por aproximações sucessivas entre quem filma e quem é filmado.

Não existiria uma contradição entre, de um lado, a tentativa de ser menos impositivo, graças ao dispositivo de elicitação de vídeo, que dá muitas referências ao espectador, e, de outo lado, o fato da equipa escolher as imagens a serem mostradas ou, de alguma maneira, de tê-las selecionado, dentre um acervo limitado, mas maior? Não teríamos imposto às pessoas falarem sobre certos assuntos, colocando-os no filme de 20 minutos que lhes mostramos? E não lhes teríamos imposto deixar de lado outros temas por estarem ausentes do filme? Parece-nos que este risco terá sido evitado com nosso guião de entrevista, que enumerou tanto o que poderia ser mencionado, porque se encontrava no filme da década de 1960, quanto o que poderia ser evocado, dado o espanto da equipa face à sua ausência no filme. Colocámos ao entrevistado a questão de saber se, na sua opinião, essa ausência se deveu à desatenção do realizador da novela para um problema que, no entanto, estava repleto de significado, ou se se referia a uma ausência de importância dessa questão para os atores sociais "verdadeiros". As reações dos entrevistados referiam-se a essas duas alternativas de forma equivalente. Nestas condições, é possível considerar que o repertório de filmes mobilizáveis para uma pesquisa por elicitação de vídeo é amplo, limitado somente pela presença de imagens demasiado fantasistas, que arruinariam a legitimidade do apelo do investigador para o discernimento do entrevistado em vista a "dizer a verdade" do arquivo fílmico.

\section{UM JOGO COM A IDENTIFICAÇÃO NA FICÇÃO}

Naturalmente, a ficção audiovisual inspira-se na arte dramática para promover fenómenos de identificação. Mas a intervenção do investigador no dispositivo da entrevista produz uma espécie de efeito disruptivo, o Verfremdungseffekt de que Brecht (2000) falou, um distanciamento para evitar uma simples catarse e para provocar uma reflexão do espetador sobre si próprio. Este efeito mantém no espetador uma consciência crítica que interpela a realidade que o filme dá para ver. Em seguida, a imagem animada e dialogada, sendo indiscutivelmente polissémica, reenvia cada pessoa à sua singularidade enquanto espectador. Conduz cada um à expressão legítima de um intertexto, de um contexto de existência que confere significado à sua receção do filme. E é precisamente essa expressão que o sociólogo etnógrafo pesquisa. A própria forma de escrita cinematográfica, com as suas elipses, promove esta expressão pessoal, recolocando regularmente a sua experiência na mente do interlocutor-espetador. Na verdade, a elipse é útil no cinema tanto para economizar tempo de exposição que o romance pode incluir, quanto para apoiar a atenção do espectador. A elipse dinamiza a atividade cognitiva deste último, que é chamado a imaginar o que aconteceu, e o que pode muito bem ter acontecido entre os dois momentos justapostos. Ele é despertado seja para procurar confirmações, naquilo que se segue, do que acha que aconteceu no intervalo da elipse, seja para que, no caso de indícios que contrariem o seu prognóstico, o espetador reúna 
elementos visando recompor a sua compreensão. Para construir essas hipóteses, ele naturalmente mobiliza o seu conhecimento da gramática da ficção, literária ou audiovisual, adquirida na sua experiência como leitor e espectador. Essa gramática serve para descartar certos pressupostos que são demasiado complexos ou, pelo contrário, demasiado óbvios. Mas, acima de tudo, o espetador mobiliza o que ele acha que sabe sobre o mundo apresentado na novela para dissipar algumas hipóteses e para manter as outras como plausíveis. Especialmente quando este mundo se situa perto do seu, social ou profissionalmente. E é precisamente a rememorização desta consciência prática (Giddens, 1987), deste conhecimento de experiência, que o pesquisador quer coletar e discutir na entrevista, com base nas questões que a situação apresentada no filme representa para o entrevistado-ator-espectador.

Ao usar a vídeo-elicitação a partir das imagens de ficção, o investigador associa de outra forma os atores sociais à pesquisa. O pesquisador abandona a sua posição dominante como especialista. Inicialmente, ele pede ajuda ao entrevistado para qualificar as imagens selecionadas, e afirma saber pouco sobre o grau de realismo das mesmas. Ele reconhece a capacidade do interlocutor para julgar, uma peritagem plena que deriva da sua experiência direta deste mundo. Não é o entrevistado que está a ser questionado, mas a imagem. Diante dela, o interlocutor encontra-se ao mesmo tempo livre da sua perceção e certo da atenção que o pesquisador lhe confere. Assim, durante a entrevista, ao falar sobre a sua experiência como desenhador num escritório de design envolvido em projetos sobre questões militares, um entrevistado aposentado, parecendo muito reservado na sua relação com o pesquisador, permite-se exclamar sobre a novela: "é realmente cinema, hein!" Esta réplica, que parece desqualificar o dispositivo, encaixa-se perfeitamente nos repertórios que o entrevistado tem permissão para usar face às imagens que o pesquisador lhe mostra. A particularidade destas imagens é a de misturar o real e o falso com cenas filmadas em lugares que os entrevistados reconhecem, nos quais os profissionais se tornam figurantes, o que provoca no espectador uma sensação de continuidade ainda mais forte entre ficção e realidade. O entrevistado pode afastar algumas imagens porque as considera abrandadas. Nesse caso, ele faz isso, a fim de evocar, no processo, uma situação relacional que ele conheceu e que é extremamente próxima daquela que é apresentada na telenovela, e que fala dos seus colegas de trabalho com uma dureza de caráter muito semelhante àquela das personagens. Este distanciamento proporcionado pelo filme é para o entrevistado uma maneira de afirmar solenemente a natureza muito tensa da situação de trabalho que ele experienciou pessoalmente: com chefes engenheiros renomados, como na novela, muito determinados e autoritários, como na novela, envolvido em rivalidades intermináveis, como na série, na qual ele acaba pagando o preço, encontrando-se "deixado de lado", "esquecido" em algum momento da sua carreira. A referência à novela permite que, ao afastar-se dela, seja possível levar a sério, enfatizar e caracterizar aspetos da experiência que provavelmente seriam perdidos sem isso: pela necessidade de retificar uma imagem considerada injusta e não apenas falsa. 
O uso da imagem de ficção como suporte para a manutenção também liberta o entrevistado de uma imagem de extrema seriedade associada à ciência. O início da projeção com uma entrevistada, uma enfermeira aposentada no complexo nuclear, fornece um sinal do desconforto frequentemente gerado pela relação do inquirido com o sociólogo. A sua procura não está claramente ligada a uma experiência já vivida, e a sua curiosidade assenta em grandes hábitos de reserva e discrição sobre si mesma. Este facto é percebido pela maneira como o medo do mal-entendido é revelado e dissipado neste caso. Nos primeiros minutos da visualização, a entrevistada pergunta, "eles são atores, não é?" (Fournier, entrevista pessoal, 13 de julho de 2015). O investigador responde-lhe positivamente e ela continua: "porque eu pensei [que, para verdadeiros engenheiros e técnicos] eles atuam bem" (Fournier, entrevista pessoal, 13 de julho de 2015). Aqui ela testemunha a sua dificuldade em acreditar que o pesquisador lhe mostra uma simples ficção romanesca com personagens fictícios. Ela tem necessidade de que lhe confirmem isso para confirmar que é realmente da sua própria experiência, por mais fútil que ela seja aos seus olhos, que o investigador quer falar, e não apenas da experiência dos seus chefes, nas suas epopeias técnicas. As imagens da novela servem assim como garantia desta expectativa, de certa forma, confusa para ela, desse interesse por práticas ordinárias que a entrevistada pode considerar irrisórias. A partir daí, pode-se rir, gozar certas imagens, enquanto a entrevistada certamente não iria querer rir do investigador, especialmente se ele pertence a um mundo social "superior" ao dela. Quando o investigador sublinha ao entrevistado que um certo plano do filme sobre uma bela residência se refere à habitação construída especialmente para os trabalhadores nucleares, ela não hesita em comentar: "sim. Aquelas ainda são muito boas. Porque algumas delas..." (Fournier, entrevista pessoal, 13 de julho de 2015).

A imagem não tem poder inerente para reduzir a distância social entre o investigador e o entrevistado, mas o seu significado está relacionado com o contexto de visualização e, neste caso, a sua mobilização no dispositivo de investigação sociológica fornece imagens suficientes à entrevistada para dar sentido à relação assimétrica que estabelece com o investigador. Esta situação desloca-se para uma relação de assistência, de atenção cruzada e de coprodução de entendimento sobre situações complexas, em vez do simples fornecimento de informações em resposta a uma solicitação.

\section{Cî̂NCIA PÚBLICA E ARTE PÚBLICA}

Entramos naquilo que propomos nomear de uma ciência pública na linha do que M. Burawoy chama de sociologia pública (2005). É pública nos seus desafios, pública nas suas modalidades de produção participativa, envolvendo as partes interessadas numa atenção comum, e pública nas suas modalidades de expressão, usando uma linguagem que não vira as costas à linguagem natural e que visa uma ampla partilha de ganhos de compreensão.

A vídeo-elicitação de imagens de ficção pode ser vista como um dispositivo de investigação capaz de interessar outros sectores de pesquisa para além das Ciências 
Sociais. Por exemplo, os membros de um comité económico e social de uma empresa poderiam usá-lo quando desejassem produzir uma história social da instituição por ocasião de um aniversário ou de uma reestruturação, ou mesmo de um encerramento, no mesmo espírito que que levou o comité económico e social de Sanofi-Romainville a recorrer a um escritor, Sylvain Rossignol, para escrever Notre usine est un roman no encerramento do site (2009). Da mesma forma, uma população local poderia encontrar uma maneira de questionar a ação de planeamento dos seus representantes eleitos ao longo do tempo, se dispusesse de imagens de ficção filmadas no seu território e as mostrasse aos seus habitantes. Este empreendimento de valorização dos arquivos de ficção, compartilhados de forma mais intuitiva do que os arquivos de papel, poderia estar na origem de um movimento de patrimonialização de uma paisagem urbana, na mesma linha dos painéis de informação destinados a turistas que se encontram hoje na proximidade de pontos de interesse cultural, apresentando uma antiga fotografia do lugar para mostrar o que resta dele e aquilo que mudou com o tempo e com a atividade dos homens, por forma a contar uma prática passada. Desta vez, não é apenas o lugar-paisagem que se torna o objeto de reflexão. Este não é apenas o objeto da prática, preservado e colocado em contexto pelo eco-museu. É a ação humana ordinária tal como é esboçada por um realizador num projeto de entretenimento, e de exploração da alma humana para este fim, buscando ecos por meio da curiosidade e com a experiência própria do espectador, até fabricar uma realidade de... película e de pixel.

Estes arquivos, hibridizados pelo diálogo com os peritos do ordinário que constituem os atores sociais familiares dos lugares, estimulados por imagens de vídeo e gerados pelo investigador-elicitador, poderiam ser vistos em smartphones, por exemplo, tanto a partir da leitura do $Q R$-Code, de alertas virtuais, quanto através de sinalizações nas redes sociais. Esses materiais de uma ciência pública poderiam, assim, ganhar um estatuto de arte pública, a partir de imagens de arte cinematográfica ou televisiva. Seria um modo de impulsionar ainda mais o movimento proposto pelo Museu Gendarmerie em Saint-Tropez para os filmes de Jean Girault, do Château d'If em relação ao romance de Alexandre Dumas e da Villa Malaparte de Capri para Jean-Luc Godard. Por outro lado, a prática contemplativa associada à arte "privada" se redobraria de formas de envolvimento cidadão para alertar sobre os conteúdos, ou mesmo pela expressão de comentários pessoais sobre ficção a propósito da sua dimensão realista, quando nos aproximamos do Outro através do ponto de vista de um artista, aqui multiplicado e compartilhado com atores comuns-especialistas.

Nestas circunstâncias, a ciência pública (vídeo-elicitação) aparece como mediadora de uma nova forma de arte pública, juntamente com as instituições de conservação e disponibilização de arquivos de imagens de ficção, para fornecer novas modalidades de expressão artística que encontrem o interesse de um público adepto a novas tecnologias e o envolvimento na busca de uma autenticidade improvável, ou mesmo na sua própria produção.

Tradução: Pedro Andrade 


\section{Agradecimentos}

Esta pesquisa beneficiou de um financiamento da missão para a interdisciplinaridade do CNRS no âmbito do programa "Nucléaire, risques et société" do "Défi Nucléaire, énergie, environnement, déchets et société", e de um apoio do governo francês para o "Programme Investissements d'Avenir, Initiative d'Excellence d'Aix-Marseille Université - A*MIDEX".

\section{REFERÊNCIAS}

Bourdieu, P., Chamboredon, J.-C. \& Passeron, J.-C. (1968). Le métier de sociologue. Paris, La Haye: Mouton.

Brecht, B. (2000). Écrits sur le théâtre. Paris: Gallimard.

Burawoy, M. (2005). For public Sociology. American Sociological Review, 70, 4-28. https://doi. org/10.1177/000312240507000102

Cesaro, P. \& Fournier, P. (2015). De la fiction faire science. Mobiliser un feuilleton télévisé des années 1960 pour parler autrement du travail dans le nucléaire. Images du travail, travail des images, ı. Retirado de http://imagesdutravail.edel.univ-poitiers.fr/index.php?id=556

Collier, J. Jr. \& Collier, M. (1967). Visual Anthropology: photography as a research method. Albuquerque: University of New Mexico Press.

Flaherty, R. (Realizador). (1922). Nanook of the North [Filme]. Estados Unidos da América.

Fournier, P. (2012). Travailler dans le nucléaire. Enquête au cœur d'un site à risques. Paris: Colin.

Girard, V. (2017). Le vote FN au village. Trajectoires de ménages populaires du périurbain. Paris: Éditions du Croquant.

Giddens, A. (1987). La constitution de la société. Eléments de la théorie de la structuration. Paris: PUF.

Keigel, L. (Realizador). (1968). Les Atomistes [Série]. França: ORTF.

Rossignol, S. (2009). Notre usine est un roman. Paris: La Découverte.

Rouquier, G. (Realizador). (1946). Farrebique [Filme]. França.

Rouquier, G. (Realizador). (1983). Biquefarre [Filme]. França.

Schaeffer, J.-M. (1999). Pourquoi la fiction ? Paris: Seuil.

Schaeffer, J.-M. (2002). De l'imagination à la fiction. Vox poetica. Lettres et sciences humaines. Retirado de http://www.vox-poetica.org/t/articles/schaeffer.html

Theureau, J. (2010). Les entretiens d'autoconfrontation et de remise en situation par les traces matérielles et le programme de recherche "cours d'action". Revue d'anthropologie des connaissances, 2, 287-322. https://doi.org/10.3917/rac.010.0287 


\section{NOTAS BIOGRÁFICAS}

Pascal Cesaro é Professor Associado de Estudos Cinematográficos na Universidade de Aix-Marseille e realizador de documentários. Ensina a teoria e a prática da realização de documentários. Investigador no Laboratório PRISM - Perceção Representações Imagem Som Música (Universidade Aix-Marselha, França), questiona o uso do filme como ferramenta de pesquisa nas Ciências Humanas e Sociais. A sua atividade desenvolve-se através de projetos de investigação-ação sobre práticas cinematográficas que podem ser qualificadas como colaborativas e acerca de maneiras de filmar o trabalho, nomeadamente no universo da saúde.

ORCID: https://orcid.org/o0oo-0003-3238-2958

Email: pascal.cesaro@univ-amu.fr

Morada: Laboratoire Perception, Représentations, Image, Son et Musique, Université d'Aix-Marseille, CNRS, Marseille, France

Pierre Fournier é professor de Sociologia na Universidade de Aix-Marseille. Ensina sociologia do trabalho e forma estudantes na pesquisa de terreno em Sociologia. No Laboratório de Sociologia Mediterrânica (Universidade Aix-Marselha, França) realiza pesquisas sobre indústrias de risco (energia, farmácia, química) e os seus territórios e, além disso, acerca de questões relativas a palavras de ordem sobre defesa do ambiente e estratificação social. Publicou Travailler dans le nucléaire (2012) e Les travailleurs du médicament (2014, coordenado com C. Lomba e S. Muller). As suas pesquisas caracterizam-se pelo uso combinado de vários métodos: observação direta, entrevistas, análise de arquivos, tratamento de dados quantitativos.

ORCID: https://orcid.org/oooo-0002-8614-4253

Email: pierre.fournier@univ-amu.fr

Morada: Laboratoire Méditerranéen de Sociologie, Université d'Aix-Marseille, CNRS, Aix-en-Provence, France

\section{Submetido: 04/09/2019}

Aceite: $30 / 11 / 2019$ 